\title{
LETTER
}

\section{Cardiopulmonary resuscitation after traumatic cardiac arrest - there are survivors: registries must speak about it}

\author{
Adriano Peris, Simona Biondi and Giovanni Zagli* \\ See related research by Gräsner et al., http://ccforum.com/content/15/6/R276
}

We read with interest the paper published in Critical Care by Gräsner and colleagues that strongly emphasizes the importance of encouraging attempts at cardiopulmonary resuscitation (CPR) in cardiac arrest caused by severe trauma [1]. Despite the interesting content, in our opinion the results presented by Gräsner and colleagues suffer by being derived from databases designed for different purposes (Cardiac Arrest Registry and Trauma Registry). The Cardiac Arrest Registry is a recording system triggered by the code cardiac arrest, while, in presence of trauma, cardiac arrest usually represents the exit code.

In our experience, cardiac arrest due to major trauma can also require extracorporeal life support (ECLS) [2]. At our tertiary referral hospital (Careggi Teaching Hospital, Florence, Italy), an ECLS algorithm-guided program has been extended to major trauma since 2009. Since then, 20 trauma patients (mean \pm standard deviation age $46 \pm 22$ years, Injury Severity Score $57 \pm 17$ ) underwent either veno-arterial ECLS (15/20 patients) or veno-venous ECLS (5/20 patients). In 10 out of 20 trauma patients, veno-arterial ECLS was established during CPR for in-hospital cardiac arrest. This subgroup of trauma patients had severe injuries (mean Injury Severity Score $58.3 \pm 15.4)$, frequently head injuries $(70 \%)$ and a shock state $(70 \%)$. Cardiac arrest occurred in six patients within 6 hours from the traumatic event, in one patient after 8 hours and in three patients after 24 hours. The overall mortality rate was $80 \%$.

Our data highlight that the lack of data from registries does not support operators in decision-making on posttraumatic cardiac arrest.

\section{Authors' response}

Jan-Thorsten Gräsner and Rolf Lefering

The letter of Peris and colleagues suggests including ECLS in the treatment algorithm for severely injured patients with CPR. We support any initiative to improve the outcome of severely injured patients, especially those with CPR, since their survival rates are usually underestimated as being close to zero. Our results show that on average seven out of 100 patients survive, at least two patients with a good outcome. This may serve as a benchmark for future research.

However, the fact that our two registries were initially established for different purposes does not necessarily exclude their appropriateness for this joint research

*Correspondence: giovanni.zagli@unifi.it

Anaesthesia and Intensive Care Unit, Emergency Department, Careggi Teaching Hospital, Largo Brambilla 3, 50134 Florence, Italy project. Although not based on a single patient group, the relative results from each registry that we combined, such as return of spontaneous circulation rates or survival rates, are valid and similar to published rates (for example, a $7.6 \%$ survival rate [3]).

\section{Abbreviations}

CPR, cardiopulmonary resuscitation; ECLS, extracorporeal life support.

\section{Competing interests}

The authors declare that they have no competing interests.

\section{Published: 21 September 2012}

\section{References}

1. Gräsner JT, Wnent J, Seewald S, Meybohm P, Fischer M, Paffrath T, Wafaisade $A$, Bein B, Lefering R: Cardiopulmonary resuscitation traumatic cardiac arrest - there are survivors. An analysis of two national emergency registries. Crit Care 2011, 15:R276.

2. Arlt M, Philipp A, Voelkel S, Rupprecht L, Mueller T, Hilker M, Graf BM, Schmid $C$ : Extracorporeal membrane oxygenation in severe trauma patients with bleeding shock. Resuscitation 2010, 81:804-809. 
Peris et al. Critical Care 2012, 16:449

Page 2 of 2

http://ccforum.com/content/16/5/449

3. Pickens JJ, Copass MK, Bulger EM: Trauma patients receiving CPR: predictors of survival. J Trauma 2005, 58:951-958. doi:10.1186/cc11348

Cite this article as: Peris A, et al:: Cardiopulmonary resuscitation after

traumatic cardiac arrest - there are survivors: registries must speak about it. Critical Care 2012, 16:449. 